\title{
The Labyrinth as Significant Form: Two Paradigms
}

Sed uisne rationes ipsas inuicem collidamus? Forsitan ex huius modi conflictatione pulchra quaedam ueritatis scintilla dissiliat.

Let us set our arguments against each other and perhaps from their opposition some special truth will emerge.

Boethius, Consolation of Philosophy 3pr12.25

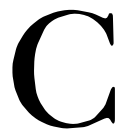

HAPTER 1 examined the major classical texts that defined and transmitted the physical facts and narrative implications of the labyrinth to later ages. A recurrent theme in that discussion was the maze's inherent duality as the embodiment of simultaneous artistry and confusion, order and chaos, product and process, depending on the observer's (or the writer's) point of view. So far, we have looked at the principle of labyrinthine duality chiefly as it manifests itself within the written tradition, although allusions have been made to the contrasting witness of the visual arts. Now it is time to expand our understanding of the labyrinth's insistent duality and convertibility by confronting directly the dramatic formal conflict between the multicursal model generally assumed by literature and the unicursal model affirmed by the visual arts. Boethius (ca. 480-524 A.D.), great reconciler of apparent contradictions, presents Lady Philosophy's remedy for this kind of conflict: "Let us set our arguments against each other and perhaps from their opposition some special truth will emerge." 1 So too here: the baffling discrepancy between visual and literary paradigms of the labyrinth, surprisingly enough, offers the key to a fuller appreciation of the idea of the labyrinth in classical and medieval times.

1. Boethius, The Consolation of Philosophy, trans. Richard Green (Indianapolis: BobbsMerrill, 1962), 3pri2 (p. 72). 


\section{- A Clash of Paradigms .}

As I have suggested, numerous visual depictions of labyrinths survive from antiquity: on prehistoric rock carvings (plate 1), on a Linear B tablet from Pylos, on sixth-century Egyptian seals, on the Tragliatella pitcher (plate 2), on Hellenistic coins, on gems, in a graffito on a house in Pompeii, and on Roman floor mosaics all over Europe and North Af rica (plate 3). Of ten these representations stand free of any mythological context, but sometimes they are explicitly or implicitly linked with the Cretan legend: the graffito, perhaps a flamboyant variation on "Beware of Dog!" is labeled "Labyrinth: the Minotaur lives here"; coins may combine maze and bull's head; pavement labyrinths, of which more than fif ty survive, are sometimes framed by scenes from the legend or enclose the fight between Theseus and the Minotaur. Most ancient labyrinths are unambiguously two-dimensional, diagrammatic, showing the maze's pattern as viewed from above. Some mazes, of ten categorized as the "Cretan type," are circular, others rectangular; most have clearly defined centers, but a few contain just a corner or loop where the wanderer would reverse direction. Some are simple in structure, having only one axis around which the path curves continually, where others are more complicated, being divided by axes into four or more segments through which a maze-walker would pass sequentially. Naturally these variants, in appropriate permutations and combinations, have elicited formal taxonomies that need not concern us here. ${ }^{2}$ What is most significant for present purposes is that, except for one fresco at Knossos, unknown from 1400 B.C. until Sir Arthur Evans's excavations, and a wall labyrinth (only vaguely multicursal) at Poitiers dating from the twelfth century, all classical and medieval mazes share a remarkable characteristic: they are unicursal, with no forked paths or internal choices to be seen. ${ }^{3}$

2. Several significant formal characteristics, such as the generally circular shape of the medieval labyrinth and the number of its circuits, are discussed in chap. 5 in relation to the visual witness in the Middle Ages.

3. For illustrations of and commentary on ancient labyrinths, see Matthews, chap. 8, Santarcangeli, chap. 9, and Kern, chaps. 2-6. For a classification of labyrinths by type, see Wilhelm Meyer, "Ein Labyrinth mit Versen," Sitzungsberichte der Königliche Bayerischen Akademie der Wissenschaften, 2 (1882), 267-300; Batschelet-Massini; and Kern, chap. 7. The Cretan fresco from the palace of Minos (Evans, fig. 256) offers a choice of paths but no truly false ones, for there is no clear center in this elaborate version of the key-pattern. The Poitiers maze (Kern, figs. 242-243; Matthews, fig. 55) has an entry but no center; if one takes a wrong turn at the sole opportunity for choice, one may be caught in an endless loop so long as one makes the same choice every time one passes that point; otherwise, one emerges from the maze by the path of entry. Neither the fresco nor the church labyrinth, then, is really what we now think of as a multicursal labyrinth, nor are they the sort of thing envisaged by classical literature. Indeed, Kern argues (p. 211) that the Poitiers graffito represents not the pattern of a pavement labyrinth formerly found in the cathedral but a carelessly drawn tracing of the path through a labyrinth of the common Chartres type (see plate 17). 
This strange situation has puzzled virtually every modern writer on labyrinths, for to post-Renaissance minds a maze is either multicursal or not really a maze at all. And as we have seen, written witnesses pretty generally endorse-and the poetic tradition insists on-the multicursality of the maze at Crete. For centuries, however, not one visual artist seems to have drawn a labyrinth with false turnings or multiple paths even though some classical and medieval writers, and presumably some artists, knew perfectly well that there were two radically different models of the labyrinth: the multicursal labyrinth-as-building described in literature, that complex construction with many chambers and winding paths in which one can easily get lost, and the unicursal labyrinth-asdiagram in which a single twisting path laboriously meanders its way to the center and then back out.

The inconsistency evokes singularly little explicit classical or medieval commentary, and one could easily conclude that it went unnoticed. But the problem was apparent to at least two writers, whose words are correspondingly precious. Pliny (p. 21 above) in the first century A.D. and Boccaccio in the fourteenth make a point of the contrast between the labyrinths of art and history: Pliny emphatically states that the deceptive, confusing three-dimensional Egyptian labyrinth is strikingly different from familiar two-dimensional unicursal pavement mosaics, and Boccaccio, glossing Dante's Commedia, writes, "This [Cretan] labyrinth was not made as we design ours, that is, with circles and windings of the walls, through which anyone who goes without turning round infallibly arrives at the middle and then, following the windings without turning, comes outside; but there was, and still is, a mountain all excavated within, made with square chambers so that each chamber has four doors, one in each side, each door leading to a similar room, so that a man who enters grows bewildered and does not know how to get out."4

If these distinctions were known to Pliny and Boccaccio, they must have been known to others as well, artists among them, unless we assume that every artist who placed a minotaur in the coils of a unicursal diagrammatic labyrinth was ignorant of the very story he was illustratingand that assumption is hard to accept, particularly because on occasion artists created labyrinths of some complexity and sophistication. Some

Many pavements and manuscripts include the key-pattern or meander (plate 6), usually not considered a labyrinth because of its simple design. Yet for Nonius Marcellus (fourth century A.D., compiler of the first surviving Latin dictionary), this meander is "a kind of design similar to the labyrinth"-De conpendiosa doctrina, ed. Wallace M. Lindsay (Leipzig: B. G. Teubner, 1903), s.v. meander.

4. Boccaccio, Il comento alla Divina Commedia, ed. Domenico Guerri, 3 vols. (Bari: Laterza, 1918), 2, 108. It is not at all clear what Boccaccio means by "our" walled fourteenthcentury labyrinths; but for a later rendition of what such a maze would look like, see plate 10 . 


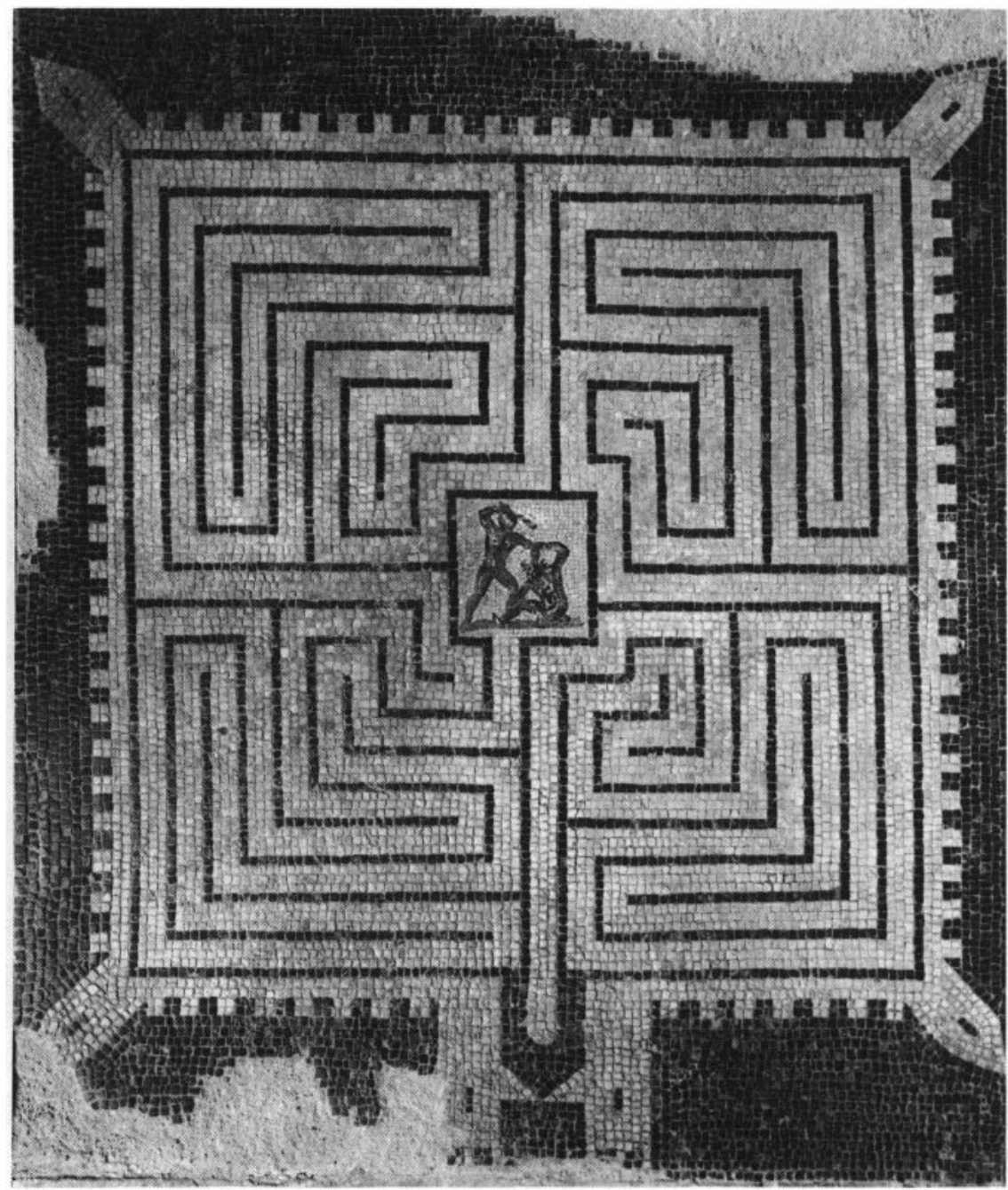

3. Roman mosaic labyrinth found in the Via Cadolini, Cremona. The crenellations and towers hint at the three-dimensional reality of the labyrinth here diagrammed. Photograph courtesy of the Soprintendenza Archeologica, Milan.

Roman pavements border their elaborate unicursal diagrams with turrets and battlements, thereby suggesting both the exterior view of a three-dimensional building and its disorienting, circuitous interior groundplan, presented as if viewed from above (see plate 3 and Kern, plates 100-103, 106-107, 109, etc.). Such artists apparently combine two points of view within one work of art, offering a visible representation of labyrinthine duality and the importance of perspective in mazy matters. 
Much later, two related medieval manuscripts offer an exterior view of the Cretan maze as a sphere crammed with crenellations, doors, and windows whose proliferation hints at the confusion that lurks within (see plate 18). ${ }^{5}$ Yet even these illustrations, reflecting in their fashion the artistry/confusion duality of the maze, do not show a multicursal diagrammatic maze pattern. Surely it would have been easy to modify a unicursal diagram, putting a false turning here or a dead end there, to create a visible illustration of the incontrovertibly multicursal Cretan maze. But no multicursal diagrams are to be found, even in explicit association with the Cretan legend, and there are no satisfactory explanations for the discrepancy between literary description and artistic realization.

True, sheer force of habit, the conservative tendency that dominates western art, may have perpetuated the traditional unicursal pattern familiar from time immemorial: if labyrinths on rocks, coins, floors, and walls, in ancient buildings and medieval cathedrals, manuscripts and fields, had always been unicursal, it would have taken a brave artist to initiate a change, no matter how well he knew Pliny, Virgil, or Boccaccio. And as John Murdoch notes, diagrams in manuscripts were often stock illustrations supplied by workshops, illuminators, or doodling casual readers who might, like paperback cover artists today, have no concern with accurately reflecting the literary content, preferring to copy stereotypes from one text and manuscript to another. ${ }^{6}$ Such considerations might explain why most pre-Renaissance mazes in the visual arts are unicursal, but why all are unicursal despite literary witnesses to the contrary remains a mystery.

Should we then conclude that the form of a maze was a matter of complete indifference to classical and medieval people and should be so to us? Pliny and Boccaccio didn't think so, nor should we. In fact, the major premise of this chapter is that we can learn a great deal about mazes from a close study of form, both the visible form of the typical unicursal design in art and the easily imagined form of the multicursal labyrinth of literature. As E. H. Gombrich has noted, form defines much of an image's symbolic potential, and that generalization is particularly true of the Middle Ages, when writers and authors were acutely alert to the significance of even such simple geometric forms as the circle, the triangle, and the pentangle. ${ }^{7}$

Therefore, this chapter explores the formal implications of the com-

5. See also Kern, chap. 6, and Hugo Buchthal, Miniature Painting in the Latin Kingdom of Jerusalem (Oxford: Clarendon Press, 1957), plates $113^{\mathrm{b}}$ and $15_{1 \mathrm{C}}$ and pp. 75-76. Kern argues simply that the ancient battlemented pavement labyrinths represent cities.

6. John E. Murdoch, Album of Science: Antiquity and the Middle Ages (New York: Charles Scribner's Sons, 1984), p. xi.

7. Gombrich, The Sense of Order: A Study in the Psychology of Decorative Art (Ithaca: Cornell University Press, 1979), p. 244. 
peting models of the maze and the logical consequences of the discrepancy between them. The incompatibility between the two paradigms, so obvious to modern eyes, might seem to create an insoluble problem or interpretive dead end. But instead, the apparent contradiction affords valuable insight into the classical and medieval concept of the labyrinth, and it does so in several ways. First, it forces us to look far more carefully at the precise implications of each model than we might have done had there been no formal conflict. Thus our understanding of metaphors involving mazes, whether unicursal, multicursal, or a blend of both, will be sharper. Second, the dearth of classical and medieval commentary on the clash of paradigms suggests that modern definitions of mazes as essentially and primarily multicursal may be far too narrow for classical and medieval ideas of the labyrinth-we may be bypassing a general category that includes both variants to focus on the mutually exclusive subcategories familiar to us. It bothers us that the same word, labyrinthus or laborintus, was unhesitatingly used to denote both unicursal diagrams in art and the multicursal Cretan maze in literature, but most medieval writers were not disturbed at all. These two pieces of evidence-the negative finding that only Pliny and Boccaccio felt a need to mention the difference in models, and the positive finding that a single signifier comfortably described two very different signifieds-force us to transcend meaningful differences and search out characteristics common to both visual design and verbal description, for these shared characteristics are precisely what define the general category "labyrinth" as it was understood in classical and medieval times, and they also constitute the physical basis for most classical and medieval metaphorical transformations of the maze image. Thus a structural comparison of the models defines the maze, highlights its symbolic potential, and provides the basis for an historically plausible taxonomy of metaphorical mazes.

If this chapter is theoretical and speculative, it is because theoretical speculation is warranted and methodologically necessary. Pliny's and Boccaccio's remarks confirm that my perception and analysis of the contrast between the models, though more detailed than theirs, is not alien to classical and medieval modes of thought. Expatiating on the implications of geometrical forms was a common medieval diversion, and solving apparent contradictions by transcending them to find a more inclusive model is also characteristically medieval. ${ }^{8}$ Although medieval people do not seem to have preserved detailed abstract reasonings about the implications of unicursal and multicursal form, they might well have had thoughts similar to those that follow. In fact, I suspect that similar analy-

8. For medieval meditations on geometrical forms, see Arthur, Medieval Sign Theory, chap. 1; see Peter Elbow, Oppositions in Chaucer (Middletown: Wesleyan University Press, 1975), for a short but useful exploration of reconciliation through transcendence in Boethius and Chaucer. 
ses formed the tacit theoretical underpinning for many uses of the labyrinth image, and that I am therefore reconstructing ideas taken so much for granted that they went unspoken. As we will see in later chapters, classical and medieval evidence - the explanations, glosses, etymologies, and metaphorical uses of the labyrinth-as-concept and the labyrinth-asvisual-symbol-confirm the conclusions reached here through formal analysis.

Yet it also remains true that most classical and medieval writers blurred or ignored the distinctions between models; their concept of "labyrinth" subsumed both models, even when the differences were clearly recognized. Assuming that mazes are by definition multicursal, we find these writers' easy acceptance of unicursal diagrams jarring in the extreme. We become fixated on the contradictions between literature and art and ignore implications of labyrinthine form that must have struck medieval people as equally important, indeed even more important. When we do so, we may be concentrating on accidentia, in the Scholastic sense: on attributes that are not absolutely necessary for a thing to $b e$ a thing. For instance, most pigs are beigy-pink, but beigypinkness is not a necessary condition for being a pig, only for being a Yorkshire pig; similarly, containing many paths is not a necessary condition for being a maze, only for being a multicursal maze. Since medieval people called both uni- and multicursal mazes laborinti, they must have seen multi- and unicursality as accidental qualities (however useful and suggestive for metaphor). What makes a maze a maze for a medieval writer, however, is something else; there must be essential qualities shared by both kinds of maze, attributes a maze must possess to be a maze at all. These essential similarities, these general characteristics found in both models, influenced creators of maze-metaphors at least as much as the differences that distinguish one subcategory from the other. Having chosen the labyrinth as a vehicle for metaphor, metaphor-makers were free to draw upon any accidental characteristic of either model appropriate to their metaphors.

Our search, then, is initially for the implications-chiefly structural, but also metaphorical - of each model, next for the essential qualities they have in common that define the classical and medieval idea of the labyrinth, and finally for reasons why the peaceful coexistence of the two models was positively advantageous to writers and artists alike. Accordingly, I begin with a brief examination of each model, considered abstractly as if it were a three-dimensional structure (references to specific instances and texts will come in later chapters; here I want to keep the theoretical argument as uncluttered as possible). As the labyrinth is both artistic product and confusing process, we must employ a kind of double vision here. Some comments will assume a privileged and objective overview-the clear understanding of the maze's complex pattern that is 
available only to the enlightened. Other comments will reflect the bewildered subjective perspective of someone enmeshed in disorienting paths and unable to determine at the point of entry whether the maze is unicursal, multicursal, or even a maze at all.

\section{- The Multicursal Model •}

The multicursal maze, as we have seen, apparently derives from literary tradition; its mythological trappings and form would have been familiar chiefly to the literate. ${ }^{9}$ Its structural basis, in contrast, is familiar to everyone: as the term "multicursal" suggests, this kind of maze is a series of choices between paths. Classical writers knew a great deal about the bivium, the Herculean or Pythagorean choice represented by the letter $Y$, with one road leading gently to pleasure and the other austerely to virtue; Christian writers would lend the image biblical authority by referring to Matthew 7:13-14, the choice between the broad path to destruction and the narrow way to life (to name only one of many biblical examples of the metaphor). ${ }^{10}$ The multicursal labyrinth is even more rigorous, however, for it does not consist of a single crucial choice; rather, it incorporates an extended series of bivia, an array of choices. It embodies frequent testing and repeated confrontations, with no apparent end to the struggle until the goal or the entry is achieved. Hence this type of maze is a perfect symbol of intellectual and moral difficulty as well as aesthetic complexity. The characteristic quality of movement through such a maze is halting, episodic, with each fork or alternative requiring a pause for thought and decision. The direction of movement is constantly shifting, now here, now there, as the wanderer's choices and the maze's paths lead him (or her, although most maze-walkers in classical and medieval literature are male). In addition, a maze-walker may lose confidence, retrace his (or her) steps, take another path, right or wrong. The essence of the maze experience is confusion, doubt, and frustration as one ambiguity succeeds another. Uncertainty may be heightened in that the maze-walker without a guide cannot know until reaching the end that the chosen path is correct; indeed, he or she cannot even be sure there is an end or center. The multicursal maze is dangerous even if no minotaur is lurking, for one risks getting lost and

9. In the following discussion, readers may want to imagine being inside a labyrinth of the sort they must have solved in puzzle books as children, or they may wish to refer to plate 4 , which shows an extremely simple multicursal maze in which success depends partly on choosing the right point of entry and partly on making correct choices within.

10. For other discussions of the Pythagorean letter, see Cipolla, Labyrinth, pp. 42-47, and Erwin Panof sky, Hercules am Scheidewege, Studien der Bibliothek Warburg, 18 (Leipzig and Berlin, 1930). 


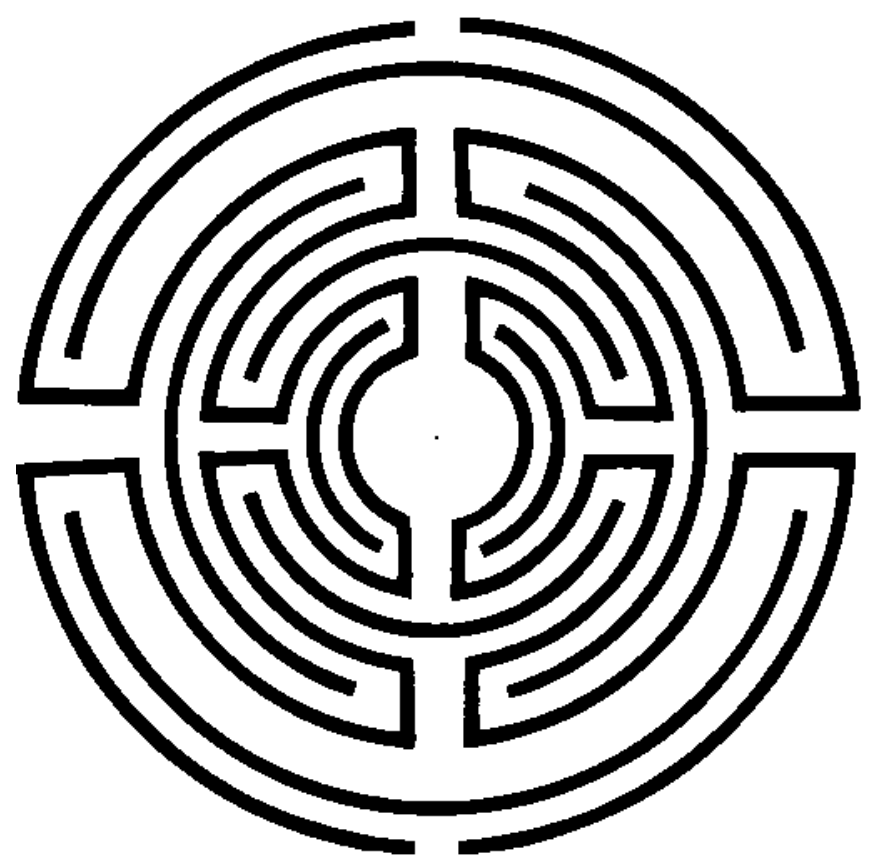

4. Example of an early multicursal labyrinth, adapted from Claude Paradin's Dévises hérö̈ques (1551). The original includes a Virgilian text, "Fata viam invenient" (the fates will find a way-Aeneid 3.395). Drawing by Robert Ouellette.

remaining perpetually imprisoned; in such a maze one may find no solution, no center, no exit. The maze, then, is potentially inextricable, as so many classical and medieval texts insist; survival and escape may well depend not only on the maze-walker's intelligence, memory, and experience but also on guidance-Ariadne's thread, instructive principles, signposts, or advice along the way. ${ }^{11}$

But who is responsible for the wanderer's success or failure? In some contexts, blame might attach to the maze-maker who created a sadistically impossible design, to the maze itself as an intrinsically deceitful ("anceps") structure, or to guides who fail to materialize, give bad advice, or lure the wanderer into the maze in the first place. Normally, however, the multicursal maze highlights the role of the individual: he controls his

11. See Borgeaud for the intriguing idea-albeit one I have found explicitly in no classical or medieval texts-that the route into a maze is inevitable, but the route out, thanks to "forgetfulness," is "suddenly complex" and demands memory or other assistance: "The Open Entrance," pp. 22-23. The sudden shift Borgeaud intuits is, perhaps, yet another instance of the unpredictable convertibility of the maze as an image. 
passage through the maze by his ability to choose and perhaps by memory, and however puzzled and despairing he may be, his fate is as much the result of his (ab)use of free will as it is a consequence of the architect's devious design. Both models of the maze entail structural error or wandering: but in a multicursal maze more obviously than in a unicursal one, these errores are not merely circuitous paths but also errors of judgment (when the wrong path is chosen) or of memory and concentration. The multicursal maze leaves most choices to the wanderer, and consequently it emphasizes an individual's responsibility for his own fate.

This labyrinthine paradigm is clearly analogous to other images associated with the maze in literature: the crossroads, the forest, the desert, the ocean, an interlace pattern, a series of caves, any confusing or trackless waste with superabundant choices and no unambiguous path, places from which safe exit is difficult or impossible without a guide or Daedalian wings. Analogous processes include such things as a chivalric quest with optional adventures, the composition or exegesis of a text or argument, and the attempt to make sense of too many pieces of data at once. Morally, the experience of multicursal mazes can be positive (the wanderer learns or accomplishes something important and transcends the confusion of the maze); negative (the wanderer chooses badly, fails miserably, and remains imprisoned); or neutral (the path through the labyrinth is the only way to get from $\mathrm{A}$ to $\mathrm{B}$, but the process and goal carry no moral connotations).

\section{- The Unicursal Model •}

The unicursal model, familiar in most periods and cultures from prehistoric times, comes from the visual arts and is part of popular culture rather than an exclusively learned model. Its structural basis is a single path, twisting and turning to the point of desperation but entailing no dead ends or choices between paths. The maze-walker simply goes where the road leads, for the maze itself is an infallible guide to its own secrets, defining precisely the only course that can be taken. The pattern is not difficult to follow, then, although its complexity means that the wanderer may not know where he is going and how he is getting there. The characteristic quality of movement through this model is steady and continuous; any flagging is caused by the wanderer's exhaustion rather than by the need for choice. The direction of movement varies as the path reverses its orientation; but where a multicursal maze contains routes to the center that are more and less direct, depending on whether the right choices are made along the way, a unicursal maze by its very nature defines the most circuitous route conceivable within any given space, the longest possible way to get to the center. In most surviving 


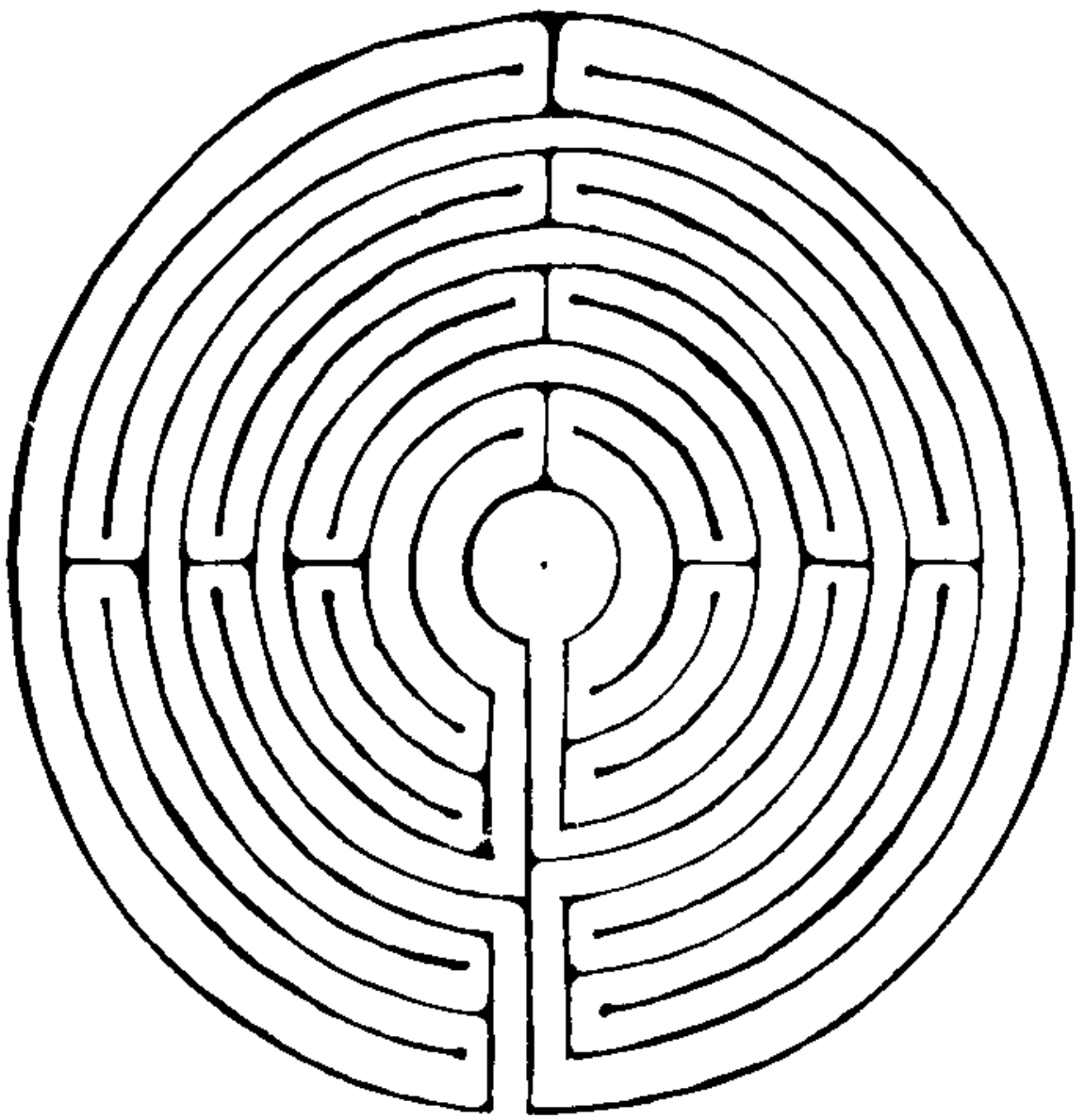

5. Typical circular unicursal diagrammatic labyrinth of the so-called Chartres type; illustrates that many mazes were designed with compasses and also shows clearly how the pattern is derived from symmetrical interruptions of concentric circles. Note that upon entering the maze, one almost immediately would near the center, only to recede farther and farther until the final successful approach. From a manuscript (ninth and eleventh centuries) from Auxerre containing numerous texts on heresy. Paris, Bibliothèque Nationale MS. lat. 1745, fol. 3ov. By permission.

unicursal designs, the path leads in and out repeatedly so that, ironically, one may unknowingly be closer to the goal as the crow flies early in the journey than when one is almost through the course. Full of unavoidable delays, a unicursal maze is a perfect symbol of the need for the patient endurance of unpredictable twists of fate. Only persistence can achieve the desired end (assuming that the end of a particular maze is desirable; 
that is not always the case). The maze itself is the truest guide, but encouragement may be needed lest the wanderer retreat in despair; alternatively, if the goal poses a threat rather than release, incitement to retrace one's steps may be appropriate.

The essence of the unicursal maze experience, as with the multicursal, is confusion and frustration. But in a unicursal maze, confusion results from inherent disorientation rather than from the repeated need for choice, and frustration is directed toward the structure and its architect rather than toward one's own incapacities. The road itself seems too long, increasingly so as one inevitably nears the unseen goal-though the wanderer might well not be certain there is a goal, or that he wants to reach it.

In a unicursal maze, obviously, there is by definition no danger of getting lost. It takes no special skill, other than constitutional perseverance, to emerge at the goal or exit; the labyrinth is not inextricable, however inescapable its turnings may seem subjectively. But there are other dangers. Perhaps there is a minotaur threatening its own kind of inextricability; indeed, we shall see that many unicursal mazes contain death, the devil, or hell. Such mazes also hold the danger of immobility and despair, the temptation to stop short of a desirable goal.

A multicursal maze usually makes the wanderer and his own errors of judgment responsible for his fate; in a unicursal maze, individual responsibility diminishes. One's wanderings (errores) in such a maze may be merely physical, prescribed by the circuitous path, although sometimes wandering in itself suggests moral culpability: errors, strayings from the straight and narrow. If the multicursal wanderer actively determines his course (although his choices are usually limited by fixed alternatives), unicursal labyrinths enforce passive dependence on the whim of the maze-maker who has already plotted the path; thus the unicursal wanderer must submit completely to the structure. The multicursal maze exemplifies the constant choice demanded of an individual, but the unicursal pattern describes the inevitability to which everyone in that particular maze must be subject. In effect, a unicursal maze-walker is Everyman, not an individual.

But if the unicursal labyrinth in itself involves no choice except whether to continue, it nevertheless implies at least one choice: whether to enter in the first place. (Initial choice also exists with a multicursal maze, but its impact is lessened by the continuing sequence of equally important choices.) A number of critical choices are located within a multicursal maze, but a single crucial choice may be located before the entrance to a unicursal maze. If the multicursal maze is an emblem of continual choice, the unicursal maze may represent a single decision as momentous as the Herculean or Pythagorean dilemma. Choosing to enter a unicursal labyrinth abrogates all future decisions except the decision to 


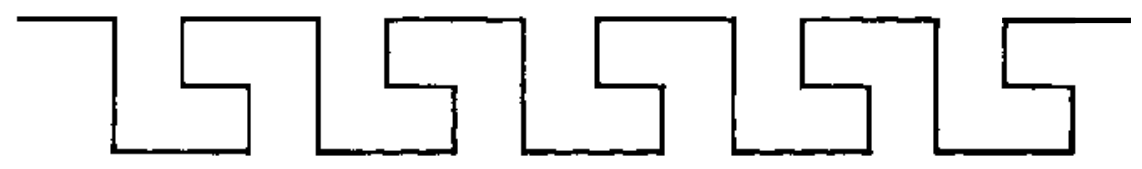

6. The Greek key pattern or meander. Drawing by Robert Ouellette.

retrace one's steps, if there is time to do so before the maze-walker reaches the center or confronts the Minotaur; it commits one to a terrifyingly unforeseeable course of events during which one is subject to the power of the maze and the will of its builder. The unicursal path is technically simple but potentially even more horrif ying than the multicursal path, in which one retains some power to choose. Thus the unicursal maze, like the multicursal, can easily become a prison where a wanderer requires guidance, even though that guidance is most aptly given before entry or as counsel to turn back.

Structures analogous to the unicursal maze are comparatively few: the winding road, the meander, and the key-pattern (see plate 6) come to mind. If the choice to enter is an aspect of structure, then the unicursal maze resembles a single bivium, not a series. Analogous experiences and processes range from life itself, fatalistically conceived, to the temporally linear reception of a literary text or philosophical argument (if choices of interpretation are ignored and the literal level is emphasized). In the moral realm, the unicursal labyrinth can be positive, with connotations of patience in adversity (the saintly wanderer is committed to "the way, the truth, and the light" and performs a convincing imitation of Christ; Christian precepts for the virtuous life may define a single if complicated path analogous to a unicursal labyrinth, as we will see in Prudentius); it can be negative, involving persistence in folly (an ignorant, careless, or evil maze-walker embarks on the deceptively simple primrose path to hell); or it can be neutral (one follows a consistent if involuted mental process or argument doggedly to its logical conclusion).

\section{- The Essence of the Maze •}

At first glance, the unicursal and multicursal paradigms involve so many differences that it is hard to imagine how the same word could apply to both. One contains a single path, the other many; one proves patience, the other tests intelligence or intuition; one is virtually inextricable, the other easy to escape, at least in theory. Looking deeper, however, we find more than sufficient similarities to explain why classical and medieval people included both models in the category "labyrinth." 
In what follows, as in my discussion of each model individually, I focus on abstract implications of the labyrinth as a structure in order to clarify the issues; in later chapters we will examine illustrative texts. I apologize in advance for an inevitably labyrinthine characteristic of the following remarks: as in a multicursal maze, we have to go over some of the same ground more than once to explicate the complicated subject.

Classical labyrinth texts reveal the labyrinth's duality: embodying both superb design and unfathomable chaos, its elaborate complexity causes admiration or alarm, depending on the observer's point of view and sophistication. This dual potentiality is inherent in unicursal and multicursal mazes alike. Anyone immersed in either mazy process and unable to see the pattern whole will become disoriented and confused, either by endless choices or by the dizzying turns of the single path that distort all sense of direction. Yet viewed from above, considered as product rather than process, either design seems admirably intricate and, most likely, highly symmetrical: an image of order containing and controlling magnificent complexity. ${ }^{12}$ Both designs are thus planned chaos, examples of artistic elaboration that baffles or dazzles according to the beholder's perspective (and the architect's skill).

Metaphor can exploit either or both of these elements. Sometimes, especially in classical and early Christian literature, the labyrinth represents only the artistry of well-structured complexity and consequently is completely praiseworthy. Conversely, when the labyrinth is an emblem of chaos alone or of artistry gone wrong, as in many medieval writings, its connotations are entirely negative. Most interesting, however, are labyrinth metaphors that involve both elements of the paradox, artistry and chaos. Sometimes the opposing qualities are simply balanced: what to the naive seems confusing is to cognoscenti incomparable design. More often, a process of moving from one point of view to another-a kind of convertibility-is implied. The normal maze experience, and certainly most process- and progress-oriented maze metaphors, envisage a perspective-mediated conversion from disorder to order: as Strabo found order in the Egyptian maze by looking down upon it, so anyone viewing the diagram of a labyrinth or experiencing and then comprehending it can understand its principles and structure and appreciate its artistry. But sometimes order disintegrates into chaos: as Daedalus was puzzled by his own construction, so too those who have studied the diagram of a multicursal or even a unicursal maze would grow confused upon experiencing its three-dimensional realization. Many maze metaphors focus on this process of conversion from confusion to admiration,

12. I am assuming that a multicursal maze, had any been drawn in classical and medieval times, would have been an adaptation of the unicursal pattern, preserving its nearsymmetry: see plate 5. Certainly the manuscripts showing an exterior view of a spherical maze (plate 18) and the descriptions by Pliny and Boccaccio suggest symmetry in the multicursal design. 
or vice versa. A few makers of moral or intellectual labyrinths (Prudentius, perhaps Boethius and Dante, the author or authors of La Queste del Saint Graal, possibly some builders of cathedral mazes) take the process even further, implicitly imagining the conversion of a multicursal to a unicursal path: if one passes successfully through a multicursal labyrinth without retracing one's steps, a mapping of one's travels would describe a unicursal pattern: multiplicity still exists in the maze itself, but the correct choices of the maze-walker define a single path that others can follow. ${ }^{13}$ I stress, however, that with very few exceptions, classical and medieval literature give no sense that one model is in moral or aesthetic terms intrinsically superior to the other.

If unicursal and multicursal mazes alike are dual, containing perspective-dependent artistry and chaos, each quality being convertible to its apparent opposite, they also share a structural feature that helps create that dual potentiality: a complicated series of winding passages. Both models are based on the concept of the path, the journey from beginning to end; both imply a sequence of movements or perceptions, usually designed intentionally as a sequence; and both may involve choice, although the nature, implications, and prominence of that choice vary greatly. But whether the labyrinth consists of a single path or many, whether choice is paramount or ignored, the course from entry to center is profoundly circuitous, turning to and fro and covering much more ground than is necessary to get from one point to another. The word most of ten used to describe this circuitous labyrinthine process is ambages. Related to ambo ("two," "both") and ambiguitas ("equivocation," something with a double sense) through the root ambi- ("around," "roundabout"), the word itself suggests the dual potentiality that characterizes so many aspects of the labyrinth. The Oxford Latin Dictionary lists the meanings of ambages:

1 (a) A roundabout or circuitous path, course, etc., meanderings, twists and turns [the labyrinth of Aeneid 6.29 is the first example given]

(b) a roundabout or circuitous movement, wandering to and fro;

(c) (applied to various long, involved, or fluctuating processes; to an intricate system of beliefs; to a tortuous scheme). Long-winded, obscure or evasive speech, a circumlocution, digression, evasion. . . . 14 Mental confusion or uncertainty.

13. This curious conversion of the multiple to the single may help explain why church labyrinths, of ten carrying significance in bono, are unicursal: Christ remedied the false turnings of sinners by taking the right path through a maze of worldly choices and temptations, thus defining an effective route to salvation and transcending earthly and infernal labyrinths. The unicursal maze preserves that single path.

One person's definitive reading of a complicated polysemous text might also involve an analogous conversion from multiplicity to specificity.

14. Lewis and Short add "ambiguity" as an alternative meaning here. 
Ambages is therefore a singularly appropriate key word in many descriptions of labyrinths and labyrinthine processes, with ambiguus a popular choice as well. Both models of the maze fully exemplify this crucial feature: their passages are invariably roundabout, although the multicursal labyrinth may be doubly ambiguous in of fering alternative paths. The labyrinth's incorporation of ambages is, then, a more inclusive and, I would argue, a more categorically important characteristic than whether the maze of fers one or a number of paths. If "labyrinth" applies equally to unicursal and multicursal mazes, then one essential labyrinthine characteristic for classical and medieval writers is the path's circuitousness, its digressiveness, its detours, delays, and diversions. A labyrinth must be circuitous in process, it must have ambages; those ambages may be simply roundabout, as in a unicursal design, or they may involve doubleness, choice, uncertainty. Anything circuitous-a multiepisodic quest, an ornate and highly amplified text, a complex piece of logic-is labyrinthine in this sense, and since neither model permits straightforward access to the center, both partake of labyrinthine ambages. How a maze-walker copes with ambages, and whether there are directions, will determine what he learns, whether he emerges successfully, and what his final perception of the labyrinth will be-order or chaos.

It is, of course, impossible in this discussion completely to separate labyrinthine form from function and objective apprehension of the whole from subjective experience of a sequence of the parts. But in order to isolate other important qualities shared by unicursal and multicursal models, I turn from an emphasis on what the labyrinth objectively is - a complexly structured convertible artifact with a circuitous pattern-to a closer look at what the labyrinth subjectively does to those inside. This topic involves a feature of the labyrinth we have so far slighted: its center. Most labyrinths-in literature and in art, unicursal and multicursal-have a center, whether or not the maze-walker is aware of it. ${ }^{15}$ In a real sense, a labyrinth asserts the presence of order in apparent chaos, if one can only see it. There is a grand maze-maker, a Daedalus, be he divine, diabolical, or human, and that maze-maker has so structured the work of art that its circuitous toils lead to a goal, good or ill, enlightening or destructive. Most mazes are designed on behalf of, and in subordination to, their centers. Labyrinths are teleological, obviously and explicitly so when they are unicursal: persistence necessarily attains the goal. But multicursal mazes also contain a route to the center, although a guide may have to supplement sheer perseverance if the traveler is to find it. Even multicursal mazes designed to be so long and

15. As Jesse M. Gellrich suggests, "The insistence on fixed and centered structure . . is obvious in many medieval notions, such as the axis mundi, the navel at the center of the world, the geocentric cosmos, and the New Law of Charity (maintained as the organizing principle of every chapter and book of the Bible)"-The Idea of the Book in the Middle Ages: Language Theory, Mythology, and Fiction (Ithaca: Cornell University Press, 1985), p. 48. 
confusing that only the elect can solve them-mazes intended to be more or less impenetrable-have a center containing something so valuable or so shameful as to warrant protection. 16

The fact that mazes have centers does not imply that every mazewalker knows there is a center: maze-walkers may not even know they are in a maze, especially when it is a metaphorical one. Nor does the existence of a center imply that everyone will reach it, even if the maze is unicursal; and reaching the center does not guarantee that one can get out again. The possible relationships between the maze-walker and the center or exit help us identify several common functions of the labyrinth and, consequently, some shared characteristics of both paradigms that define the full idea of the labyrinth and its metaphorical potential.

First, the maze may be intended to imprison those who enter, either before they reach the center (the maze is impenetrable) or afterward (the maze is inextricable), by entrapping them in its coils, perhaps as prey for the Minotaur. Such a maze is almost by definition in malo, at least from the point of view of the victim. It is easy to see how a three-dimensional multicursal maze could be impenetrable and inextricable in practice, however possible it may be in theory to escape. Indeed, "inextricabilis" and "inexplicabilis" are as commonly descriptive of mazes as "ambages." At first glance, however, it is hard to see how a unicursal labyrinth could be either impenetrable or inextricable, even though diagrammatic illustrations of the Cretan myth invariably show single-pathed mazes. A hungry minotaur can make any maze inextricable, of course, but there is another solution, one that involves changing one's point of view. Subjectively, anyone in either type of three-dimensional labyrinth and ignorant of its pattern may perceive it as impenetrable and/or inextricable, whether it is so in fact or not. Even in a unicursal maze, by definition penetrable and extricable, one feels imprisoned by the curving walls, by one's narrowly limited view ahead and behind. One's movement, like one's vision, is severely constricted, for whether there is one road or many, one

16. One cannot take centers for granted in the labyrinths of our own century: perhaps the fear that there is no center after all is part of the terror of the maze. Indeed, the absence of a center may be even more threatening than the presence of a minotaur, for reasons that Jacques Derrida explores: "The function of [a] center was not only to orient, balance, and organize the structure-one cannot in fact conceive of an unorganized structure-but above all to make sure that the organizing principle of the structure would limit what we might call the play of the structure. By orienting and organizing the coherence of the system, the center of a structure permits the play of its elements inside the total form. And even today the notion of a structure lacking any center represents the unthinkable itself": "Structure, Sign, and Play in the Discourse of the Human Sciences," in Writing and Difference, trans. Alan Bass (Chicago: University of Chicago Press, 1978), pp. 278-293, here pp. 278-279. Derrida goes on to note that "the center . . can be either inside or outside, [and] can also indifferently be called the origin or end" (p. 279). Philippe Borgeaud makes the suggestive if limited point that "the labyrinth always has two centers: where one is and where one desires to be"- "The Open Entrance," p. 23. This statement is really true only if "center" is used metaphorically as "goal," and only from the subjective point of view of a wanderer in an unpleasant maze. 
cannot strike out in any direction one pleases or leap out of the maze entirely. Thus both models are subjectively impenetrable and inextricable prisons, at least while one is in them, and most labyrinth metaphors stressing inextricability involve a subjective or psychological component; some labyrinths - those of sin, for example-are woven by the mazewalker himself, either directly or because he has rendered himself prey to Satan of his own free will. (Both paradigms are appropriate here, though their nuances differ: one can choose to enter a unicursal path of sin that leads inevitably to the prison of hell at the center; or one can repeatedly choose the wrong path of a multicursal maze and end disastrously. Here as elsewhere, the imagined form of a metaphorical maze normally has no intrinsic correlation in bono or in malo.)

If mazes can be prisons, they can also be useful, difficult, carefully structured paths leading somewhere important, even if that place is finally outside or beyond the labyrinth (labyrinths are almost always places one wants to escape, either to avoid danger and confusion or to attain a more comprehensive perspective). The labyrinth-as-prison is a process of ambages from which one cannot, or thinks one cannot, escape; but there is also a labyrinth with a happy ending, a metaphorical labyrinth-as-progress, carefully shaped by a master architect to direct the worthy wanderer to a profitable end: the path, the choices between paths, the prescribed errores, all are designed to carry the wanderer over just the right territory to achieve something that could not have been reached by a direct route. The architect knows that a certain process is necessary if the wanderer is to get where the architect wants him to go and learn what should be learned. If the maze is unicursal, the architect has calculated the precise sequence of turns and disorientations needed for the wanderer to appreciate the center when he gets there. If the maze is multicursal, the architect has foreseen alternative routes, some of which may lead to failure for people who cannot learn, concentrate, remember, and choose properly; but other paths may prove and perfect the wanderer before providing enlightenment, which may well be presented as mental or physical extrication from the labyrinth, a rising above it to see its pattern, and a transformation of confusion into understanding.

Focusing on the subjective experience of the maze-walker, however, shows a more frightening picture. The maze-walker may be involved in a process of confusion for his own good, but he is nevertheless confused, perhaps the more so in proportion to the good he may achieve. Even if the labyrinth was designed to be extricable, it will not seem so-in fact, it will be a labyrinth precisely because it feels inextricable, aimless, confusing. Its very point is to impose a confusing and difficult process on someone because that extraordinarily baffling process is just what it takes to prepare the maze-walker for moral, aesthetic, or intellectual transcendence. As T. S. Eliot said in a context not wholly dissimilar, 
In order to arrive at what you do not know

You must go by a way which is the way of ignorance. ${ }^{17}$

Both models delineate the way of ignorance-ignorance of the path, the pattern, the goal, the maze-maker's intentions. Whether there are choices and guides or not, one cannot know what lies around the next curve until one gets there; means dominate ends, process obscures product, and the wanderer must continue, choose, or retreat with no sure knowledge of the consequences. Yet if the maze-maker is being fair, then the maze-walker, by his very perseverance, withdrawal, or choices, will find the goal he deserves: success or failure, imprisonment or escape, confusion or understanding. This subjective if temporary ignorance of path and goal, this intense immersion in process, is yet another important labyrinthine characteristic shared by both models and generating numerous metaphors, many of them involving epistemology. Few if any images of a planned path through ignorance to understanding are better than the labyrinth, and both models describe the path equally well, if with the subtle difference that a unicursal maze-walker follows a universal and authoritative curriculum whereas a multicursal wanderer participates more actively and selectively in his own education. In a unicursal maze one learns by precept; in a multicursal maze, by dialectic.

This chapter began with the assumption that the formal aspects of labyrinths and the apparent contradictions between models were important; we followed, as it were, each of two opposing paths in a multicursal maze. Tracing the complexities of a maze's paths may lead to an appreciation of its magnificent design, to new knowledge facilitated by experiencing and then transcending confusion; so too here, where the ambiguities of the two paradigms have begun to resolve themselves into a clearer, more privileged vision of their commonality. If the apparently happy and usually tacit coexistence of both types of labyrinth under one name can be taken as evidence that shared features are more important in defining the idea of the labyrinth than features peculiar to one model-if we move beyond subcategorical distinctions to categorical imperatives-we may reconcile the conflicting paradigms by identif ying those shared characteristics. The most important characteristics common to both models seem to be these:

I. Pertaining to the labyrinth as artifact, as objective pattern:

a. The labyrinth's dual and convertible potentiality as a sign of confusion (within) and of complex artistic order (without or above); the

17. T. S. Eliot, The Four Quartets, "East Coker," 11. 140-141, quoted from The Complete Poems and Plays (New York: Harcourt, Brace, 1952). There are clearly potential similarities between the labyrinthine path to knowledge and the mystical via negativa, but I will not explore them here. 
labyrinth as magnificent handiwork of a superlative architect, once it is properly and comprehensively perceived;

b. The labyrinth's structural principle: confusing ambages, circuitousness, ambiguity; the presence of physical, intellectual, or moral errores;

II. Pertaining to the labyrinth as subjective process, as path(s) surrounding an unseen goal or center:

a. Real or apparent impenetrability and inextricability; the labyrinth as prison, at least for some maze-walkers;

b. The path of ignorance; difficult but necessary process and progress that may lead to knowledge, transcendence, extrication.

Such are the primary and defining qualities of a labyrinth of either model in the classical and medieval periods: each has an architect, benevolent or malevolent, whose artistry is manifested in a construction with a circuitous and therefore confusing pattern that bewilders the ignorant as it delights the knowledgeable. Each model seems inextricable and impenetrable, depending on what lies within and whether the wanderer persists or retreats, choosing right or wrong once (in deciding to enter a unicursal maze) or repeatedly (in a multicursal maze). Each may lead the worthy wanderer toward a conversion from confusion to perception. These are the essential qualities of a maze; any labyrinth, real or metaphorical, must have all or most of them to be considered a labyrinth at all.

Both models, then, share enough common qualities to justify inclusion in a common category. In fact, the preceding discussion has almost defined the differences between models out of significant existence: although a characteristic may be highlighted in one model, it is always at least latent in the other. Apparent distinctions turn out to be matters of degree rather than of kind, accidental, in the Scholastic sense, rather than essential. A multicursal maze stresses repeated choice, but a unicursal model implies a choice-possibly a critical choice-to enter. Unicursal mazes emphasize the rewards of persistence, but that virtue may be equally necessary in a multicursal labyrinth. Multicursal mazes are more obviously inextricable, but an intelligent wanderer can theoretically solve them and escape, and even unicursal mazes can be efficient prisons. Guidance is of ten crucial in multicursal mazes, but it may be helpful in unicursal ones as well. ${ }^{18}$

We return, then, to the question with which we began this chapter. Why do the visual arts show unicursal labyrinths rather than multicursal

18. Some readers may wonder why I have not therefore included choice, the need for persistence, and the usefulness of external guidance as essential qualities of the maze. I have not done so because although these qualities are theoretically and potentially present in both models, they are normally developed only in one or the other. Few literary treatments of a traditionally multicursal maze such as the Cretan one, for instance, play with the idea of perseverance, and many uses of the unicursal maze ignore initial choice completely. 
ones? If the question still has no definitive answer, it can be addressed more confidently now we have explored and transcended the contradictions between paradigms. I suggest the main reason for the absence of multicursal diagrammatic labyrinths in art is that there was no real need for them: the unicursal design found in mosaics, fields, churches, and manuscripts conveyed the labyrinth's essential qualities so effectively that there was no real pressure to modify the time-honored design. ${ }^{19}$ Unicursal patterns may be as symmetrical and ornate as multicursal ones, and they connote artistry just as well. They are just as circuitous, as full of ambages. They may also be just as confusing and inextricable to the eye: a maze of either type is, in Gombrich's term, a "restless figure," 20 a pattern that pulls about our vision incessantly. Whether or not a diagrammatic maze possesses false turns, the complexity of the design may be vaster than the eye can comprehend in a glance, for the eye can focus on only part of a complicated field at one time: "A highly redundant design of identical elements offers no easy anchorage for our apparatus on which to 'lock in.' It drifts and loses its place." 21 True, a unicursal diagrammatic pattern is not, to onlookers, a path of ignorance. But it does give an enlightened overview of difficult process, facilitating both our imagined immersion in twisting paths and the eventual transcendent perception of the whole that brings comprehension and appreciation.

The unicursal diagram does well enough to convey the idea of the maze, and it has powerful historical precedent in art. The best solution that can be found to the mystery is that classical and medieval eyes saw insufficient difference in the implications of the two models to warrant a new design. Why, then, did maze-makers in the sixteenth and seventeenth centuries suddenly start to draw multicursal mazes? In their quest for historical authenticity, the humanists may have wanted to make their illustrations a more accurate reflection of classical texts, so they replaced the old-fashioned medieval representation-generally unicursal and diagrammatic-with multicursal or architectural (three-dimensional) models. In addition, the popularity of Hercules at the Crossroads as a Renaissance motif may have superceded the unicursal design, which carries much the same message of single exemplary choice. The multicursal maze, stressing repeated individual choice, may have developed as a useful complementary image. Whatever the reason, Renaissance and Baroque maze-makers did their revisionist work so well that their more restricted version of the maze became definitive. ${ }^{22}$ Since their time, to

19. As we will see in chap. 5 , there may have been multicursal three-dimensional buildings.

20. Gombrich, Sense of Order, chap. 4.

21. Sense of Order, p. 131.

22. For Hercules, see Panofsky, Hercules am Scheidewege; Kern also suggests that the appearance of multicursal mazes in mid-sixteenth-century art may derive from a wish to make art correspond to literary texts (p. 99). 
our loss, western culture has focused narrowly on repeated choice as the single essential characteristic of a maze.

The richest, most potent, most adaptable signs are those that of fer the widest and most subtly nuanced array of characteristics to be drawn upon and modified by those who use and interpret them. The more options, the better, so long as the general import of the sign's potential is clear-and we have seen that in the case of the labyrinth, it is clear. What Augustine said of the joys of multiple verbal meanings in scriptural interpretation applies equally to a visual or conceptual sign like the labyrinth:

[Sometimes] things signify not one thing but more, and not only two diverse things, but sometimes many different things in accordance with the meaning of passages in which they are found. ... When ... not one but two or more meanings are elicited, even if what he who wrote the passage intended remains hidden, there is no danger if any of the meanings may be seen to be congruous with the truth taught in other passages of Holy Scriptures. . . . For what could God have more generously and abundantly provided in the divine writings than that the same words might be understood in various ways which other no less divine witnesses approve?23

The existence of many signifying possibilities in the labyrinth gave authors and interpreters a great deal of flexibility, and they took full advantage of it. Two models are richer than one.

Classical and medieval people thus did well to accept both models as equally labyrinthine. Writers, if not purveyors of diagrams, had as an easily available option the use of a clearly unicursal or clearly multicursal maze, and the choice of one or the other might ef ficiently accentuate certain features-the importance of guidance or intelligence as opposed to patience in adversity, a single or repeated choice, determinism or free will. But even for the majority who did not concern themselves with the differences between models, the historical presence of alternatives was no less beneficial. The impressively diverse metaphorical potential of the classical and medieval labyrinth may well have been a consequence of the existence of two identically named paradigms whose superficial incom-

Huston Diehl ("Into the Maze of Self: The Protestant Transformation of the Image of the Labyrinth," JMRS, 16 [1986], 281-301) discusses Renaissance labyrinth imagery in literature and art and argues that the maze's significance changed with the Protestant emphasis on man's dependence on God's grace to escape damnation. Diehl's argument is based on a narrow view of the medieval maze (solely as represented in cathedral labyrinths) as "a spiritual experience" of "meaningful action" whose "destination is known, desired, and spiritually rewarding" (p. 284). This oversimplification of the medieval idea of the maze vitiates Diehl's analysis of "Protestant" mazes. Moreover, he does not directly address the issue of uni- and multicursality, nor does he relate these models to his conjecture that Protestant mazes reveal man's inability to help himself find salvation.

23. Augustine, On Christian Doctrine 3.25-27 (pp. 101-102). 
patibilities created an irresistible pressure to fuse the two by transcending their differences. This conflation and reconciliation of models, each with powerf ul traditional authority from literature or from art, was what made the idea of the labyrinth so rich, flexible, and useful.

Form does matter, then, even if it is of ten ignored, even if usually there is no question of hierarchy or of development from one model to another. Thus our initial examination of the two models as if they were diametrically opposed was not the setting up of a straw man. But form has turned out to matter in a different way from what we may have expected: it probably forced the development of a more inclusive concept of the labyrinth, and it has provided us with a method for discovering what that concept is, expanding our horizon of expectations.

Perhaps it is appropriate to comment here on another aspect of the labyrinth in the visual arts: the implications of most artists' decision to depict the labyrinth diagrammatically rather than as a three-dimensional structure. ${ }^{24}$ The diagram of a maze simultaneously shows magnificent pattern and convoluted process, effectively imaging the artistry/ confusion paradox; as with optical illusions, we may find ourselves flashing back and forth between perceptions of the whole and its parts, thereby experiencing labyrinthine convertibility. Because we can see the artistic whole, intermittently at least, the labyrinth's confusing process is counterbalanced by an assurance that a great maze-maker, a controlling artist, planned the maze so that it has order, a path to a stable center, a promise of rest within. A diagrammatic labyrinth paradoxically clarifies its own confusion; it holds structural design and the psychological tensions created by that design in perfect equilibrium, suggesting order in chaos, the purposefulness of apparent aimlessness, unity controlling multiplicity. A diagrammatic representation does a better job of illustrating several of the labyrinth's essential qualities than do threedimensional illustrations, and that may help explain why diagrams are much more numerous.

In this chapter, then, a Boethian "special truth" has emerged from the apparent conflict of paradigms, reconciling unicursal and multicursal designs, artistic and literary tradition. Primary characteristics and secondary implications of the models have provided us with an inclusive mapping of the idea of the labyrinth as well as a sensitivity to possible nuances and minor distinctions that may assume major importance in individual cases. We have begun to explore the abstract basis for the rich symbolic potential of classical and medieval labyrinths. As constructs well and elaborately designed, mazes are emblems of great artistry; by the same token, they may exemplify the appalling confusion that results when a creator's talents or a perceiver's analytical skills are insufficient to

24. The implications of most medieval labyrinths' circularity will be discussed in chap. $\mathbf{5}$. 
meet the challenge. As processes involving a constant interplay between authority (the pattern channeling the maze-walker along previously determined courses) and the individual (who, even in a unicursal maze, may play the game or not), they are superb models for the consequences of single or multiple moral, intellectual, and hermeneutic choices exercised within some constraints and leading finally to freedom or to imprisonment. As structures that of ten intend and describe changes in perspective, they are models for enlightenment or for the process of learning the order (moral, intellectual, or aesthetic) that gives meaning and form to apparent chaos. Unified entities composed of discrete but linked parts (the length of path that lies between turnings), they image multiplicity and unity, parts and the whole, means and ends, always depending on one's point of view and sophistication. The inclusive classical and medieval idea of the labyrinth allows an author to combine aesthetic and moral process, object and subject, authority and experience. It even integrates within one coherent and comprehensive image divine and authorial intention (the architect's plan), the resulting construct (the world-maze, the text-labyrinth), and the human being's, or reader's, or hearer's response (the experience, choices, and conclusions of the mazewalker). If there is nevertheless a Derridan aporia present in the simultaneous affirmation of a unicursal and a multicursal model-and I think there very well may be-this is not the place to deconstruct the maze. ${ }^{25}$

25. If I were to indulge in deconstructive fancy, I would argue that the implicit simultaneous af firmation of both models in the Middle Ages received so little contemporary attention because it constitutes an important aporia: a self-contradiction that, if recognized, could turn the edifice of orthodox theology into a flimsy house of cards. As we will see, the labyrinth of ten represents the course of life from birth to death and the fixed order of God's created universe. In this context, the multicursal model makes an orthodox statement about man's relationship to God and to his own fate: God designs the master plan, the paths and laws within which individuals, aided perhaps by grace, ecclesiastical instruction, or the sacraments, choose their own course and thus their own ends: entrapment and damnation or extrication and salvation. This model illustrates the interactions of divine ordinance and human free will. The unicursal labyrinth, on the other hand, is potentially heterodox, more appropriate in a classical, fatalistic context: God establishes an inevitable pattern that all who enter must follow, so that individual free will is irrelevant. This model, then, is deterministic; yet it is the model appearing even in cathedrals and sacred manuscripts.

Certainly one can devise arguments that get around the free will-determinism impasse: perhaps the goal in the multicursal model is eschatological, heaven or hell, whereas the goal to which all must come in the unicursal model is death. Perhaps the choice to enter and persist in a unicursal labyrinth constitutes a free choice to move toward heaven or hell, depending on whether this particular labyrinth is in bono or in malo. Nevertheless, I suspect that the general medieval ref usal to conf ront the different implications of each model may owe something to fear of what a closer inquiry might discover. Far easier to accept both models and blur the distinctions, especially when, by so doing, one satisfies another important medieval impulse by "valuing the universal over the particular and the typical over the individual"-A. J. Minnis, Medieval Theory of Authorship, p. 2. 
My goal has been more modest: to extrapolate the classical and medieval definition of the maze from the examination and juxtaposition of its two models. The following chapters consider the metaphorical fruits of these labors, the transformations and varied meanings of particular mazes and metaphors. 